\title{
Comprehensive systematic review update summary: Disorders of consciousness
}

\author{
Report of the Guideline Development, Dissemination, and Implementation \\ Subcommittee of the American Academy of Neurology; the American Congress of \\ Rehabilitation Medicine; and the National Institute on Disability, Independent \\ Living, and Rehabilitation Research
}

Joseph T. Giacino, PhD, Douglas I. Katz, MD, Nicholas D. Schiff, MD, John Whyte, MD, PhD, Eric J. Ashman, MD, Stephen Ashwal, MD, Richard Barbano, MD, PhD, Flora M. Hammond, MD, Steven Laureys, MD, PhD, Geoffrey S.F. Ling, MD, Risa Nakase-Richardson, PhD, Ronald T. Seel, PhD, Stuart Yablon, MD,

Thomas S.D. Getchius, Gary S. Gronseth, MD, and Melissa J. Armstrong, MD, MSc

Neurology ${ }^{\circledR}$ 2018;91:461-470. doi:10.1212/WNL.0000000000005928

\author{
Correspondence \\ American Academy of \\ Neurology \\ guidelines@aan.com
}

\begin{abstract}
Objective

To update the 1995 American Academy of Neurology (AAN) practice parameter on persistent vegetative state and the 2002 case definition for the minimally conscious state (MCS) by reviewing the literature on the diagnosis, natural history, prognosis, and treatment of disorders of consciousness lasting at least 28 days.

\section{Methods}

Articles were classified per the AAN evidence-based classification system. Evidence synthesis occurred through a modified Grading of Recommendations Assessment, Development and Evaluation process. Recommendations were based on evidence, related evidence, care principles, and inferences according to the AAN 2011 process manual, as amended.

Results

No diagnostic assessment procedure had moderate or strong evidence for use. It is possible that a positive EMG response to command, EEG reactivity to sensory stimuli, laser-evoked potentials, and the Perturbational Complexity Index can distinguish MCS from vegetative state/unresponsive wakefulness syndrome (VS/UWS). The natural history of recovery from prolonged VS/UWS is better in traumatic than nontraumatic cases. MCS is generally associated with a better prognosis than VS (conclusions of low to moderate confidence in adult populations), and traumatic injury is generally associated with a better prognosis than nontraumatic injury (conclusions of low to moderate confidence in adult and pediatric populations). Findings concerning other prognostic features are stratified by etiology of injury (traumatic vs nontraumatic) and diagnosis (VS/UWS vs MCS) with low to moderate degrees of confidence. Therapeutic evidence is sparse. Amantadine probably hastens functional recovery in patients with MCS or VS/UWS secondary to severe traumatic brain injury over 4 weeks of treatment. Recommendations are presented separately.
\end{abstract}

\section{RELATED ARTICLES \\ Practice guideline update recommendations summary: Disorders of consciousness: Report of the Guideline Development, Dissemination, and Implementation Subcommittee of the American Academy of Neurology; the American Congress of Rehabilitation Medicine; and the National Institute on Disability, Independent Living, and Rehabilitation Research Page 450}

Ethical, palliative, and policy considerations in disorders of consciousness

Page 471

AMERICAN ACADEMY OF NEUROLOGY.

\footnotetext{
From the Department of Physical Medicine and Rehabilitation (J.T.G.), Spaulding Rehabilitation Hospital and Harvard Medical School; Department of Psychiatry (.T.G.), Massachusetts General Hospital, Boston; Department of Neurology (D.I.K.), Boston University School of Medicine; Braintree Rehabilitation Hospital (D.I.K.), MA; Department of Neurology and Neuroscience (N.D.S.), Weill Cornell Medical College, New York, NY; Moss Rehabilitation Research Institute (J.W.), Elkins Park, PA; Bronson Neuroscience Center (E.J.A.), Bronson Methodist Hospital, Kalamazoo, Ml; Department of Pediatrics, Division of Child Neurology (S.A.), Loma Linda University School of Medicine, CA; Department of Neurology (R.B.), University of Rochester Medical Center, NY; Indiana University Department of Physical Medicine \& Rehabilitation (F.M.H.), University of Indiana School of Medicine, Indianapolis; Coma Science Group-GIGA Research and Department of Neurology (S.L.), Sart Tillman Liège University \& University Hospital, Liège, Belgium; Department of Neurology (G.S.F.L.), Uniformed Services University of Health Sciences, Bethesda; Department of Neurology (G.S.F.L.), Johns Hopkins University, Baltimore, MD; James A. Haley Veterans' Hospital (R.N.-R.), US Department of Veterans Affairs, Tampa, FL; Crawford Research Institute (R.T.S.), Shepherd Center, Atlanta, GA; Center for Rehabilitation Science and Engineering, Department of Physical Medicine \& Rehabilitation (R.T.S.), Virginia Commonwealth University School of Medicine, Richmond; Division of Physical Medicine \& Rehabilitation (S.Y.), University of Mississippi School of Medicine; Brain Injury Program (S.Y.), Methodist Rehabilitation Center, Jackson, MS; Heart Rhythm Society (T.S.D.G.), Washington, DC; Department of Neurology (G.S.G.), University of Kansas Medical Center, Kansas City; and Department of Neurology (M.J.A.), University of Florida College of Medicine, Gainesville. Go to Neurology.org/N for full disclosures. Funding information and disclosures deemed relevant by the authors, if any, are provided at the end of the article.
}

This research was supported through a memorandum of understanding among the American Academy of Neurology, the American Congress of Rehabilitation Medicine, and the National Institute on Disability and Rehabilitation Research (NIDRR). In 2014, NIDRR was moved from the US Department of Education to the Administration for Community Living of the US Department of Health and Human Services, and was renamed the National Institute on Disability, Independent Living, and Rehabilitation Research (NIDILRR). This article does not reflect the official policy or opinions of NIDILRR or HHS and does not constitute an endorsement by NIDILRR, HHS, or other components of the federal government.

Approved by the AAN Guideline Development, Dissemination, and Implementation Subcommittee on October 21, 2017; by the AAN Practice Committee on April 9, 2018; by the American Congress of Rehabilitation Medicine Board of Governors on April 30, 2018; by the National Institute on Disability, Independent Living, and Rehabilitation Research Review Committee on April 5, 2018; and by the AAN Institute Board of Directors on May 2, 2018.

This practice guideline was endorsed by the American Academy of Physical Medicine and Rehabilitation on April 4 2018; by the American College of Surgeons Committee on Trauma on July 3, 2018; and by the Child Neurology Society on April 17, 2018.

This special article is published simultaneously in the Archives of Physical Medical Rehabilitation and Neurology. Neurology was responsible for peer review of this article. 


\section{Glossary}

AAN = American Academy of Neurology; CI = confidence interval; DoC $=$ disorders of consciousness; $\mathbf{e M C S}=$ emergence from minimally conscious state; LEP = laser-evoked potential; $\mathbf{L R}=$ likelihood ratio; $\mathbf{M C S}=$ minimally conscious state; MSTF = Multi-Society Task Force; OR = odds ratio; PVS = persistent vegetative state; UWS = unresponsive wakefulness syndrome; VS = vegetative state.

In simplest terms, consciousness is defined as the state of awareness of the self and environment. ${ }^{1}$ Conscious behavior requires adequate arousal (i.e., wakefulness) and awareness of content (i.e., sensory, cognitive, and affective experience). Severe acquired brain injury $(\mathrm{ABI})$ is a catastrophic event that disrupts the brain's arousal and awareness systems, which are mediated by the brainstem and cortex, respectively. The most severe injuries result in prolonged (i.e., lasting at least 28 days) disorders of consciousness (DoC), including the vegetative state (VS) ${ }^{2}$ and the minimally conscious state (MCS). ${ }^{3} \mathrm{VS}$ is also referred to as postcoma unawareness ${ }^{4}$ or unresponsive wakefulness syndrome (UWS). ${ }^{5}$ In this guideline, the term UWS is used synonymously with VS. While this term has no special merit or mandate for use in clinical practice, it is included here because of its wide acceptance in Europe. Table e-1 (links.lww.com/WNL/A611) provides the definitions for VS and MCS and other key terms pertinent to DoC.

The cost of lifetime care for persons with prolonged DoC can exceed $\$ 1,000,000{ }^{6}$ Despite the enormity of the problem, few practice guidelines are available. In 1995, the American Academy of Neurology (AAN) published diagnostic and prognostic guidelines for persistent VS (PVS) ${ }^{7}$ following an evidence-based review completed by the Multi-Society Task Force (MSTF) on PVS. ${ }^{2}$ In 2002, the Aspen Neurobehavioral Workgroup defined MCS and published consensus-based diagnostic criteria. ${ }^{3}$ Both reports focused on diagnosis, as data addressing prognosis and treatment were sparse.

Based on available epidemiologic data, ${ }^{8}$ the annual US incidence of VS is approximately 4,200 persons. The incidence of MCS is unknown largely because it has no diagnostic code in the International Classification of Diseases classification system. Prevalence figures for VS/UWS and MCS in the United States are hampered by economic factors that lead patients with DoC to be transferred from the acute care setting to long-term care facilities, where they are often lost to follow-up. Prevalence estimates range from 5,000 to 42,000 persons for VS/UWS ${ }^{9-11}$ and 112,000 to 280,000 persons for MCS using a proxy definition. ${ }^{12}$

Published estimates of misdiagnosis among patients with DoC consistently approximate $40 \%$ in both US and European

\section{$\oplus$ Supplemental Data}

Full text of guideline at:

NPub.org/m5ii8i studies. $^{13-15}$ In the most recent study, ${ }^{13} 41 \%$ of patients with a clinical diagnosis of VS/UWS based on team consensus $(n=44)$ were actually in MCS when reevaluated by the investigators using a standardized neurobehavioral scale. In addition, $89 \%$ of those with an uncertain diagnosis $(n=18)$ were found to have clear signs of consciousness on standardized examination. Findings from the other 2 studies ${ }^{14,15}$ were in the same direction. Underlying visual or motor impairments interfering with detection of command-following and failure to detect visual pursuit are frequent causes of failure to recognize MCS. The rate of diagnostic error underscores the need for more refined evaluation methods. This concern extends to the criteria for emergence from MCS (eMCS), as some investigators suggest that the existing criteria lead to overdiagnosis of this condition. ${ }^{16}$

Now is an opportune time to reevaluate current diagnostic approaches. Apart from the extensive list of specialized neurobehavioral assessment instruments that have been released since the MSTF and Aspen Neurobehavioral Workgroup reports were published, ${ }^{2,17}$ a growing body of research suggests that functional neuroimaging techniques, such as fMRI and PET, may be able to detect suggestions of conscious awareness in the absence of bedside evidence. ${ }^{18-21}$

Natural history studies of patients with prolonged DoC now include outcomes extending beyond 1 year. This provides an opportunity to reassess the 1994 MSTF introduction of the term permanent VS (table e-1, links.lww.com/WNL/A611), which is questioned based on the methodology used to calculate the incidence of recovery of consciousness beyond 12 months ${ }^{22}$ and the total number of individuals available for follow-up after 12 months (i.e., 30). ${ }^{23}$ Increasingly, publications are also available for DoC prognosis and treatment, with recent multicenter randomized clinical trials available to determine the effectiveness of specific interventions for patients with prolonged DoC.

The purpose of this systematic review and accompanying guideline is to update the 1995 AAN PVS guideline ${ }^{7}$ and the 2002 MCS case definition. ${ }^{3}$ This article summarizes the systematic review findings and conclusions. The guideline recommendations are published separately. ${ }^{24}$ Full text of the systematic review and guideline, including appendices e- 1 to $\mathrm{e}-9$, is available as a data supplement at links.lww.com/WNL/ A610. Tables e- 1 to e- 3 and references e1 through e42, cited here, are also available at links.lww.com/WNL/A612.

This review aimed to answer 10 clinical questions (table e-2, links.lww.com/WNL/A611), which can be summarized in 4 
overarching questions concerning patients with traumatic and nontraumatic DoC: (1) What procedures accurately diagnose prolonged $\mathrm{DoC}$, where prolonged $\mathrm{DoC}$ is defined as lasting at least 28 days? (2) What is the natural history of prolonged DoC? (3) What factors or procedures help to predict outcome in prolonged DoC? (4) What treatments are effective for prolonged DoC?

\section{Description of the analytic process}

This systematic review and accompanying practice guideline were developed in accordance with the process described in the 2011 AAN Clinical Practice Guideline Process Manual, as amended. ${ }^{25}$ The full guideline provides a description of the exact methodology followed, including the processes of convening the author panel, performing the literature search, and reviewing the evidence and application of a modified Grading of Recommendations Assessment, Development and Evaluation (GRADE) process. ${ }^{26}$ Recommendations were based not only on the evidence in the systematic review, but also on strong related evidence, established principles of care, and inferences. The level of obligation for each recommendation was based on the strength of these premises and the riskbenefit ratio of following the recommendation, with adjustments based on importance of outcomes, variation in patient preferences, feasibility/availability, and patient costs. Consensus was determined by a modified Delphi voting process in accordance with prespecified rules. ${ }^{25}$

Inclusion criteria relevant for all questions were (1) population had a DoC for at least 28 days and (2) the study enrolled at least 20 patients with a prolonged DoC. The 28 day cutoff was employed to ensure that patients in coma were excluded, as good outcome is not uncommon following transient coma, unlike prolonged VS/UWS and MCS. Articles were accepted only if the entire participant population met the criterion of having a DoC for at least 28 days or if the article presented data for this cohort separately. This approach was determined a priori and resulted in the exclusion of some high-quality studies. This is discussed further in the Putting the Evidence in a Clinical Context section.

\section{Analysis of evidence}

\section{Diagnostic assessment}

For the diagnostic question, the guideline panel considered patients with traumatic or nontraumatic VS/UWS or MCS at least 28 days postinjury and asked if any diagnostic assessment procedures accurately detect behavioral signs of consciousness or differentiate specific DoC compared with standardized behavioral assessment. Readers are referred to a previously published systematic review completed by the American Congress of Rehabilitation Medicine Disorders of Consciousness Task Force that provides evidence-based recommendations for clinical use of standardized behavioral assessment methods (work not repeated in this project). ${ }^{17}$
Study results were assessed using likelihood ratios (LRs), which are described in the full-length guideline.

Eight diagnostic articles were Class I for at least some procedures, ${ }^{27-34} 4$ articles were Class II, ${ }^{29,35-37}$ and 4 articles were Class III ${ }^{38-40, e 1}$ (links.lww.com/WNL/A612). No diagnostic assessment procedure had moderate or strong evidence for use (table 1). For distinguishing VS and MCS, there was insufficient evidence to support or refute the use of EMG activity to command after adjusting for involuntary movements, $^{27}$ normal or mildly abnormal background on EEG, ${ }^{29,31}$ the combination of a low-voltage background EEG pattern and lack of EEG reactivity, ${ }^{31}$ specific entropy measures, ${ }^{38}$ the absence of $A \delta$-fiber laser-evoked potential (LEP) N2P2 or C-fiber LEP N2P2 components in response to LEPs, ${ }^{\mathrm{e} 2}$ evidence of exogenous or endogenous attention as assessed by the P3a and P3b components of P300 in response to word stimuli, ${ }^{35}$ a nasal cannula "sniff controller," 28 command-following on an fMRI motor imagery task, ${ }^{29}$ use of an $\mathrm{AMRI}$ incorrect-minus-correct activation protocol, ${ }^{36}$ resting-state $\mathrm{MRI},{ }^{37}$ structural $\mathrm{MRI},{ }^{37}$ or fluorodeoxyglucose-PET, ${ }^{37}$ often due to limited precision. It is possible that fMRI using a word-counting task is not helpful in distinguishing between MCS and VS (low confidence in the evidence, 1 Class I study, ${ }^{33}$ with the LR+ suggesting no change in the probability of MCS with testing and confidence intervals (CIs) suggesting values of slight importance at most; LR+1.00, 95\% CI 0.33-2.99). Results for this study were affected by the fact that 3 of 8 patients diagnosed with VS/UWS based on the absence of command following on the CRS-R had the suggestion of fMRI activation with the task (37.5\%, 95\% CI $13.7 \%-69.4 \%)$, the implications of which are uncertain.

\section{Natural history}

Eighteen articles $^{\mathrm{e} 3-\mathrm{e} 20}$ (links.lww.com/WNL/A612) met inclusion criteria for the natural history question. Results were analyzed separately by DoC diagnosis and etiology; studies only reporting mixed etiology populations are described in the full-length guideline. No studies examined the natural history of patients in traumatic or nontraumatic MCS in a manner allowing outcome to be determined at specific times postinjury.

\section{Natural history of patients with traumatic VS/UWS}

Eight Class III studies were identified, reporting outcomes at 3 months ${ }^{\text {e4,e12,e20 }}$ (links.lww.com/WNL/A612), 6 months, ${ }^{\text {e4,e12,e20 }}$ 8 months, ${ }^{\mathrm{e} 5} 12$ months, ${ }^{\mathrm{e} 4, \mathrm{e} 9, \mathrm{e} 10, \mathrm{e} 12, \mathrm{e} 20}$ and $>24$ months $^{\mathrm{e} 13}$ postinjury. Most studies were Class III due to recruitment from specialty rehabilitation centers, thus limiting generalizability. Results were combined in random-effects metaanalyses to result in single estimates (table 2), each reflecting low confidence in the evidence. Comprehensive results are presented in the full-length guideline.

Natural history of patients with nontraumatic VS/UWS Four Class III studies reported outcomes in patients with nontraumatic VS/UWS ${ }^{\mathrm{e} 3, \mathrm{e} 5, \mathrm{e} 13, \mathrm{e} 14}$ (links.lww.com/WNL/ A612). Six- and 24-month recovery estimates are presented in table 2. It is possible that 3-month survival for patients with 
Table 1 Conclusions regarding diagnostic assessments with evidence for use in prolonged disorders of consciousness (DoC)

\begin{tabular}{|c|c|}
\hline Diagnostic assessment & Conclusion \\
\hline EMG & $\begin{array}{l}\text { In patients with a DoC for at least } 28 \text { days, a positive EMG response to command using a threshold of } 1.5 \text { on a ratio between } \\
\text { a response to motor commands and a control command to distinguish voluntary responses from involuntary movements is } \\
\text { possibly helpful in distinguishing patients with MCS from those with VS/UWS (LR+23.0, 95\% CI 1.5-355.6) (low confidence in the } \\
\text { evidence, } 1 \text { Class I study }{ }^{34} \text { with decreased confidence in the evidence due to precision). }\end{array}$ \\
\hline EEG & $\begin{array}{l}\text { It is possible that EEG reactivity to at least one type of sensory stimulus distinguishes MCS from VS to a mildly important degree } \\
\text { (low confidence in the evidence; } 1 \text { Class I study }{ }^{31} \text { with decreased confidence in the evidence due to precision; } \mathrm{LR}+2.00,95 \% \mathrm{Cl} \\
1.43-2.80 \text { ). }\end{array}$ \\
\hline Evoked potentials & $\begin{array}{l}\text { It is possible that the presence of AS-LEP N2P2 and C-LEP N2P2 components in response to LEPs distinguishes MCS from VS to } \\
\text { a mildly important degree (low confidence in the evidence; } 1 \text { Class I study }{ }^{32} \text { with decreased confidence in the evidence due to } \\
\text { precision; LR+ } 2.30,95 \% \mathrm{Cl} 1.43-3.67) \text {. }\end{array}$ \\
\hline PCl score & $\begin{array}{l}\text { It is possible that a PCI >0.31 distinguishes MCS from VS/UWS to a mildly important degree (low confidence in the evidence, } 1 \\
\text { Class I study }{ }^{30} \text { with decreased confidence in the evidence due to precision; LR+ 3.375, 95\% Cl 1.87-6.09). }\end{array}$ \\
\hline
\end{tabular}

nontraumatic VS/UWS is $80 \%\left(95 \%\right.$ CI $\left.67 \%-93 \%, I^{2}=59\right)$ (low confidence in the evidence, 2 Class III studies). ${ }^{\mathrm{e} 3 \mathrm{e} 13}$ It is possible that $60 \%$ of patients with nontraumatic VS/UWS (95\% CI 45\%-74\%) will survive to 6-8 months (low confidence in the evidence, 2 Class III studies). ${ }^{\mathrm{e} 3, \mathrm{e} 13}$

\section{Prognostic assessment}

For the prognostic question, the guideline panel first evaluated the prognostic relevance of DoC diagnosis (VS/UWS vs MCS) and of mechanism of injury. Then, the panel separately considered prognostic factors in patients with traumatic or nontraumatic VS/UWS or MCS at least 28 days postinjury because this information has the most clinical relevance. Prognostic factors for which there was insufficient evidence are described only in the full-length guideline.

\section{Prognostic factors in adult populations}

Four Class II studies ${ }^{\mathrm{e} 6 \mathrm{e} 8 \mathrm{e}, \mathrm{e} 21, \mathrm{e} 22}$ (links.lww.com/WNL/A612) examined the prognostic value of diagnoses of MCS vs VS/ UWS. In prolonged DoC of traumatic origin, a diagnosis of MCS, as opposed to VS/UWS, is probably associated with increased odds of better than severe disability at 12 months (moderate confidence in the evidence, 1 Class II study ${ }^{\mathrm{e} 22}$ with increased confidence in the evidence due to magnitude of effect). In patients with prolonged DoC of mixed etiology, a diagnosis of MCS is possibly associated with increased odds of improvement vs VS/UWS (odds ratio [OR] 4.72, 95\% CI $1.13-19.71, I^{2}=66 \%$ ) (low confidence in the evidence, metaanalysis of 3 Class II studies ${ }^{\mathrm{e} 8, \mathrm{e} 21, \mathrm{e} 22}$ with insufficient precision to drive recommendations individually). In patients with a prolonged DoC of mixed etiology already present for over a year, a diagnosis of VS/UWS is possibly associated with increased odds of deterioration in functional status over subsequent years (OR 3.37, 95\% CI 1.28-8.87) (low confidence in the evidence, 1 Class II study). ${ }^{\mathrm{e} 6}$

One Class I and 4 Class II studies examined the prognostic value of traumatic vs nontraumatic injury in patients with prolonged $\mathrm{DoC}^{\mathrm{e} 6, \mathrm{e} 8, \mathrm{e} 21-\mathrm{e} 23}$ (links.lww.com/WNL/A612). In patients with prolonged MCS, a traumatic etiology is probably associated with increased odds of better than severe disability at 12 months (OR 11.0, 95\% CI 1.9-63.2, moderate confidence in the evidence, 1 Class II study ${ }^{\mathrm{e} 24}$ with increased confidence in the evidence due to magnitude of effect). In mixed populations including patients with MCS and VS/UWS, traumatic DoC is probably associated with increased odds of improvement (defined generally due to differences in study design; OR 9.41, 95\% CI 2.03-43.53; moderate confidence in the evidence, 3 Class III studies, ${ }^{\mathrm{e}, \mathrm{e} 21, \mathrm{e} 24} 2$ of which had sufficient precision on their own ${ }^{\mathrm{e} 21, \mathrm{e} 24}$ combined in a metaanalysis with overall increased confidence in the evidence due to magnitude of effect).

Table 2 Cumulative recovery of consciousness in disorders of consciousness (DoC) lasting $\geq 28$ days

\begin{tabular}{|c|c|c|c|c|}
\hline Type of DoC & 3 months & 6 months & 12 months & 24 months \\
\hline Posttraumatic VS/UWS & $38 \%(29 \%-47 \%)$ & $67 \%(58 \%-76 \%)$ & $78 \%(69 \%-86 \%)$ & \\
\hline Nontraumatic VS/UWS & & $17 \%(5 \%-30 \%)^{a}$ & & $7.5 \%(0 \%-24 \%)^{\mathrm{b}}$ \\
\hline
\end{tabular}


Table 3 Prognostic features in disorders of consciousness (DoC) $\geq 28$ days

\begin{tabular}{|c|c|c|c|c|}
\hline \multirow[b]{2}{*}{ Type of DoC } & \multicolumn{2}{|c|}{ Prognostic factors associated with better prognosis } & \multicolumn{2}{|c|}{ Prognostic factors associated with worse prognosis } \\
\hline & Moderate confidence & Low confidence & Moderate confidence & Low confidence \\
\hline \multirow[t]{6}{*}{$\begin{array}{l}\text { Adult traumatic } \\
\text { VS/UWS }\end{array}$} & $\begin{array}{l}\text { Higher-level activation of the } \\
\text { associated auditory cortex using BOLD } \\
\text { fMRI in response to a familiar voice } \\
\text { speaking the patient's name }\end{array}$ & $\begin{array}{l}\text { Normal SPECT scan 1-2 } \\
\text { months postinjury }\end{array}$ & $\begin{array}{l}\text { Hydrocephalus in the } \\
\text { late phase }\end{array}$ & $\begin{array}{l}\text { Corpus callosum lesions, } \\
\text { dorsolateral upper brainstem } \\
\text { injury, or corona radiata injury on } \\
\text { MRI performed 6-8 weeks } \\
\text { postinjury }\end{array}$ \\
\hline & $\begin{array}{l}\text { DRS scores of }<26,2-3 \text { months } \\
\text { postinjury }\end{array}$ & $\begin{array}{l}\text { Lower scores on the DRS } \\
\text { in general } 2-3 \text { months } \\
\text { postinjury }\end{array}$ & & $\begin{array}{l}\text { Fever of central origin in the acute } \\
\text { phase }\end{array}$ \\
\hline & $\begin{array}{l}\text { Detectable P300 at } 2-3 \text { months } \\
\text { postinjury }\end{array}$ & $\begin{array}{l}\text { The presence of P300 } \\
\text { after controlling for DRS } \\
\text { and EEG reactivity }\end{array}$ & & $\begin{array}{l}\text { Diffuse body sweating in the acute } \\
\text { phase }\end{array}$ \\
\hline & Reactive EEG at 2-3 months postinjury & & & Epilepsy in the late phase \\
\hline & & & & Respiratory disturbance \\
\hline & & & & Flaccidity in the acute phase \\
\hline \multirow{4}{*}{$\begin{array}{l}\text { Adult traumatic } \\
\text { mixed (VS/UWS } \\
\text { and MCS) }\end{array}$} & & $\begin{array}{l}\text { Faster improvements in } \\
\text { DRS scores }\end{array}$ & $\begin{array}{l}\text { Longer time post injury } \\
\text { at study enrollment }\end{array}$ & \\
\hline & & Amantadine use & $\begin{array}{l}\text { Worse DRS score at } \\
\text { study enrollment }\end{array}$ & \\
\hline & & & Dantrolene use & \\
\hline & & $\begin{array}{l}\text { Left temporal lobe } \\
\text { lesions, contusions/mass } \\
\text { lesions, or subarachnoid } \\
\text { hemorrhage on imaging }\end{array}$ & $\begin{array}{l}\text { Left frontal or bilateral } \\
\text { lesions on imaging }\end{array}$ & \\
\hline
\end{tabular}

\begin{tabular}{lll}
\hline $\begin{array}{l}\text { Adult } \\
\text { nontraumatic } \\
\text { VS/UWS }\end{array}$ & $\begin{array}{l}\text { CRS-R scores of } \geq 6 \text { more than } 1 \mathrm{mo} \\
\text { after onset }\end{array}$ \\
\hline & Presence of SEPs & \\
\hline $\begin{array}{l}\text { Adult mixed } \\
\text { traumatic and } \\
\text { nontraumatic } \\
\text { populations }\end{array}$ & $\begin{array}{l}\text { Approximate entropy value of } \geq 0.8 \text { (vs } \\
<0.8)\end{array}$ & $\begin{array}{l}\text { Higher baseline } \\
\text { composite score } \\
\text { combining the CRS-R } \\
\text { score plus points for DoC } \\
\text { subtype }\end{array}$ \\
\hline & Presence of MMN on EEG & $\begin{array}{l}\text { Mental imagery fMRI } \\
\text { Older age }\end{array}$ \\
\hline & & $\begin{array}{l}\text { Increasing complexity of } \\
\text { sleep architecture on PSG } \\
\text { performed 3.5 } \pm 2 \text { months } \\
\text { postinjury }\end{array}$ \\
\hline
\end{tabular}

\begin{tabular}{|c|c|c|}
\hline & & $\begin{array}{l}\text { Presence of } 3 \text { or more medical } \\
\text { complications during inpatient } \\
\text { rehabilitation }\end{array}$ \\
\hline $\begin{array}{l}\text { Pediatric } \\
\text { traumatic VS/ } \\
\text { UWS }\end{array}$ & $\begin{array}{l}\text { Absence of posttraumatic } \\
\text { autonomic dysfunction }\end{array}$ & $\begin{array}{l}\text { Posttraumatic hyperthermia at any } \\
\text { time }\end{array}$ \\
\hline
\end{tabular}

Prognostic factors for DoC subgroups are presented in table 3, with measures of association described in the full-length guideline. Nine studies ${ }^{\mathrm{e} 4, \mathrm{e} 10, \mathrm{e} 20, \mathrm{e} 22, \mathrm{e} 25-\mathrm{e} 29}$ (links.lww.com/WNL/A612) (1 Class I, 7 Class II, 1 Class III) were identified looking at prognostic factors in patients with traumatic VS/UWS, although 3 of the Class II studies were based on largely the same patients/study and thus were considered together. ${ }^{\mathrm{e} 10, \mathrm{e} 25, \mathrm{e} 30}$ One Class II study ${ }^{\mathrm{e} 29}$ and 1 Class III study ${ }^{\mathrm{e} 31}$ examined prognostic factors for patients with traumatic DoC in populations where patients in VS/UWS and MCS were combined. Two Class I studies ${ }^{\mathrm{e} 14, \mathrm{e} 28}$ and 2 Class II studies $^{\mathrm{e} 3, \mathrm{e} 22}$ examined prognostic factors for patients with 
nontraumatic VS/UWS. Only 1 prognostic study ${ }^{\mathrm{e} 28}$ was identified for patients in either traumatic or nontraumatic MCS; there was insufficient evidence to drive conclusions for either group. Two Class I studies ${ }^{38, e 5}$ and 7 Class II studies ${ }^{\mathrm{e} 6, \mathrm{e} 8,21, \mathrm{e} 32-\mathrm{e} 35}$ examined prognostic factors in populations with mixed etiologies (traumatic vs nontraumatic) or mixed diagnoses (VS/UWS or MCS) or both in ways that individual subgroups could not be distinguished (table 3).

\section{Prognostic factors in pediatric populations}

In pediatric patients, traumatic (vs anoxic) etiology of VS/UWS present for at least 30 days is possibly associated with increased odds of recovery at 3-12 months (low confidence in the evidence, 1 Class II study ${ }^{\text {e36 }}$ [links.lww.com/WNL/A612]). A traumatic etiology, as compared to an anoxic injury, is probably also associated with a better quality outcome (moderate confidence in the evidence, 1 Class II study ${ }^{\text {e36 }}$ with increased confidence due to magnitude of effect). In pediatric patients with a DoC for at least 90 days, a traumatic etiology, as compared with an anoxic injury, is possibly associated with better cognitive and motor outcomes and increased odds of taking feedings orally (low confidence in the evidence, 1 Class II study ${ }^{\mathrm{e} 37}$ ). Other prognostic features are described in table 3.

\section{Therapeutic intervention}

Two Class I therapeutic studies ${ }^{\text {e38,e39 }}$ (links.lww.com/WNL/ A612) and 1 Class III therapeutic study ${ }^{\mathrm{e} 0}$ were identified. Amantadine probably hastens functional recovery in patients with MCS or VS/UWS secondary to severe traumatic brain injury over 4 weeks of treatment (moderate confidence in the evidence, 1 Class I study ${ }^{\mathrm{e} 38}$ ) and appears safe in this population. There is insufficient evidence to support or refute continuation of benefit once amantadine is discontinued (very low confidence in the evidence, 1 Class I study ${ }^{\mathrm{e} 8}$ with insufficient precision). In patients with VS/UWS of mixed etiologies, conventional tilt table treatment is probably superior to tilt table treatment incorporating an integrated stepping device for improving level of arousal (moderate confidence in the evidence based on 1 Class I study ${ }^{\mathrm{e} 9}$ ), but the benefit of tilt table treatment vs placebo/nontreatment is not established (no identified studies).

\section{Putting the evidence in a clinical context}

The results of this systematic review highlight important gaps in knowledge related to diagnosis, natural history, prognosis, and treatment for patients with prolonged DoC. Some consistent weaknesses in study methodology were observed across studies, constraining the strength of the evidence. Small sample size was the most prevalent weakness due to limited study precision and generalizability.

In addition, the number of available studies was constrained by the a priori inclusion criteria of the guideline. The decision to include only studies investigating participants who were at least
28 days postinjury disqualified many studies conducted in the acute care setting, as well as those that either combined, or did not specify, the number of participants above and below this threshold. Some well-designed studies in which the majority of the participants met the 28-day inclusion criterion are considered in the rationale for recommendations as strong related evidence but could not contribute to the systematic review. Below, the guideline panel describes trends in study design within each of the 4 areas that compromised the strength of the evidence.

\section{Diagnostic assessment}

The most important challenge to validating more precise diagnostic approaches is the absence of an established reference (gold) standard with adequate sensitivity and specificity. The most commonly used reference standard (team consensusbased diagnosis) is associated with a $30 \%-40 \%$ error rate. ${ }^{13-15}$ Thus, it is difficult to discern whether disagreement between the reference standard and a novel assessment measure reflects a false-positive or false-negative error on the part of the novel measure, or evidence that the novel measure has outperformed the reference standard. A second recurrent weakness in diagnostic studies is the infrequent use of masking procedures. Masking is essential to protect against examiner bias, which is particularly important when the assessment approach relies on nonobjective measures.

\section{Natural history}

Investigation of the natural history of recovery from severe brain injury requires a systematic approach to tracking selected milestones (e.g., mortality, recovery of consciousness, improvement in degree of disability). Many of the studies failed to report or control for the length of time from injury and instead anchored follow-up to date of admission to the inpatient rehabilitation setting. A study reporting that emergence from MCS occurs an average of 45 days after admission to the rehabilitation hospital is of limited clinical utility if the time to admission ranged from 4 to 52 weeks postinjury. Studies often failed to stratify or subanalyze participants by diagnostic subtype (VS/UWS vs MCS) and etiology (traumatic/nontraumatic), obscuring the trajectory of recovery. The fact that most natural history studies enroll participants at specialty rehabilitation centers is a further limitation, as these results may not generalize to individuals without access to specialty rehabilitation services.

Finally, relatively few natural history and prognostic studies reported long-term functional outcomes. In many studies, outcome assessment focused exclusively on recovery of consciousness or eMCS or both, without attention to the corresponding level of disability. Importantly, studies that tracked functional outcome beyond 1 year suggest up to 1 in 5 patients with prolonged DoC-especially those who transition to MCS before 6 months - eventually regain independence in the home environment $^{\mathrm{e} 41, \mathrm{e} 42}$ (links.lww.com/WNL/A612). DoC outcome research will be of greater relevance to clinicians, patients, and families by ensuring that results address the degree of functional improvement attained. 


\section{Prognostic assessment}

The majority of studies investigating the predictive utility of patient and injury characteristics were conducted retrospectively, which subjected these studies to some of the same limitations noted in the natural history studies. Because inclusion criteria did not address specific clinical features known to be linked to outcome (e.g., diagnostic subtype, injury etiology, and length of time postinjury), within-sample variability tended to be high along these dimensions, contributing to wide CIs and imprecise outcome projection. In addition, risk factors and outcomes were often not assessed independently, allowing the possibility that factors believed to affect prognosis may have inappropriately influenced clinical decisions and contributed to unfavorable outcomes (including decisions to discontinue life-sustaining care).

\section{Therapeutic interventions}

Most treatment studies were excluded because the intervention was studied during the acute phase of recovery, there was no control group, or the study was not methodologically sound. DoC treatment studies face challenges not encountered in clinical trials conducted in other populations. First, the number of patients with prolonged DoC admitted to inpatient rehabilitation settings has progressively declined over the last 15 years. This trend is influenced by a number of factors, including a tendency by insurers to preferentially authorize rehabilitative care in lower-cost settings such as skilled nursing facilities. Consequently, it is difficult to enroll a large enough sample to support a sufficiently powered therapeutic study. Constraints on sample size also limit stratification of participants to account for differences in treatment effect related to mediating factors such as cause of injury, chronicity, and number of comorbidities.

A second challenge arises in the context of the rehabilitation setting. The typical length of inpatient rehabilitation in many academic medical centers has fallen below 20 days. Under these circumstances, family members are often reticent to enroll patients with prolonged $\mathrm{DoC}$ in a placebo-controlled trial in view of the $50 \%$ likelihood of assignment to the placebo arm, preventing any possibility of active treatment during rehabilitation apart from routine physical, occupational, and speech therapies.

\section{Author contributions}

Dr. Giacino: study concept and design, acquisition, analysis, and interpretation of data, drafting/revising the manuscript, critical revision of the manuscript for important intellectual content, study supervision. Dr. Katz: study concept and design, acquisition, analysis, and interpretation of data, drafting/ revising the manuscript, critical revision of the manuscript for important intellectual content. Dr. Schiff: study concept and design, acquisition, analysis, and interpretation of data, drafting/revising the manuscript, critical revision of the manuscript for important intellectual content. Dr. Whyte: study concept and design, acquisition, analysis, and interpretation of data, drafting/revising the manuscript, critical revision of the manuscript for important intellectual content. Dr. Ashman: acquisition, analysis, and interpretation of data, critical revision of the manuscript for important intellectual content. Dr. Ashwal: study concept and design, acquisition, analysis, and interpretation of data, drafting/revising the manuscript, critical revision of the manuscript for important intellectual content. Dr. Barbano: acquisition, analysis, and interpretation of data, drafting/revising the manuscript, critical revision of the manuscript for important intellectual content, study supervision. Dr. Hammond: acquisition, analysis, and interpretation of data, drafting/revising the manuscript, critical revision of the manuscript for important intellectual content. Dr. Laureys: acquisition, analysis, and interpretation of data, drafting/revising the manuscript, critical revision of the manuscript for important intellectual content. Dr. Ling: acquisition, analysis, and interpretation of data, drafting/revising the manuscript, critical revision of the manuscript for important intellectual content. Dr. NakaseRichardson: acquisition, analysis, and interpretation of data, drafting/revising the manuscript, critical revision of the manuscript for important intellectual content. Dr. Seel: acquisition, analysis, and interpretation of data, drafting/ revising the manuscript, critical revision of the manuscript for important intellectual content. Dr. Yablon: acquisition, analysis, and interpretation of data, drafting/revising the manuscript, critical revision of the manuscript for important intellectual content. T. Getchius: acquisition, analysis, and interpretation of data. Dr. Gronseth: acquisition, analysis, and interpretation of data, drafting/revising the manuscript, critical revision of the manuscript for important intellectual content. Dr. Armstrong: acquisition, analysis, and interpretation of data, drafting/revising the manuscript, critical revision of the manuscript for important intellectual content, study supervision.

\section{Study funding}

This practice guideline was funded by the American Academy of Neurology (AAN), the American Congress of Rehabilitation Medicine, and the National Institute on Disability, Independent Living, and Rehabilitation Research. Authors who serve or served as AAN subcommittee members (E.J.A., S.A., R.B., G.S.G.) or as methodologists (M.J.A., G.S.G.), or who were AAN staff members (T.S.D.G.), were reimbursed by the AAN for expenses related to travel to subcommittee meetings where drafts of manuscripts were reviewed.

\section{Disclosure}

J. Giacino has received funding for travel from the US Department of Defense for a meeting related to the TBI Endpoint Development Project; from the National Institute on Neurological Disorders and Stroke (NINDS) of the NIH for a meeting related to the Transforming Research and Clinical Knowledge in Traumatic Brain Injury study; from the National Institute on Disability, Independent Living, and Rehabilitation Research (NIDILRR) for the Traumatic Brain Injury Model Systems Project Directors meeting; from the American Academy of Physical Medicine and Rehabilitation, 
the One Mind Foundation, and the James S. McDonnell Foundation for a meeting related to the Recovery of Consciousness After Severe Brain Injury study; from the Barbara Epstein Foundation; and from the International Brain Injury Association; has received a cash donation from the Epstein Foundation for a hospital clinical program that he directs and for serving on a team that provided clinical consultation services to an overseas patient who sustained severe brain injury; has served as an editor for the Journal of Head Trauma Rehabilitation; has received honoraria from the One Mind Foundation, Holy Cross Hospital (Surrey, UK), HealthSouth Braintree Hospital, Western Michigan Brain Injury Network, George Washington University Medical School, Association of Academic Physiatrists, Mayo Clinic, Kennedy-Krieger Institute, and Magill's Medical Guide; performs clinical procedures as $10 \%$ of his clinical effort in his role as Director of Spaulding Rehabilitation Network Disorders of Consciousness Program and neuroimaging as a principal investigator on 2 neuroimaging studies for $30 \%$ of his research effort; received financial support from the NIH NINDS for Central Thalamic Stimulation for Traumatic Brain Injury, US Department of Defense for TBI Endpoint Development Project, the Huperzine A for the Treatment of Cognitive, Mood and Functional Deficits After Moderate and Severe TBI study, the Injury and Traumatic Stress (INTRuST) Consortium Neuroimaging Acquisition and Archival study, the NIDILRR for the Spaulding Harvard-Traumatic Brain Injury Model System and for Multicenter Evaluation of Memory Remediation after Traumatic Brain Injury with Donepezil, the NINDS for Transforming Research and Clinical Knowledge in Traumatic Brain Injury study, James S. McDonnell Foundation for Study of Recovery of Consciousness After Severe Brain Injury, Barbara Epstein Foundation, and the Spaulding Rehabilitation Hospital Department of Physical Medicine and Rehabilitation; and has acted as a witness with regard to a legal proceeding. D. Katz has received royalties from Demos for Brain Injury Medicine, 2013, and from Lash Publications; has received honoraria for speaking at HealthSouth/Encompass Health Medical Directors' Conference, various grand rounds on topics related to disorders of consciousness (DoC), including Harvard Longwood Neurology, Providence VA Hospital, Tufts Medical Center, Baystate Medical Center, and University of Massachusetts Medical Center, and for service as Chair, External Scientific Advisory Board, VA Rehabilitation Research and Development TBI Center of Excellence, Boston; has given expert testimony in several legal cases involving patients with DoC after brain injury; has received travel support for talks and conferences on DoC from organizations, including World Federation of Neurorehabilitation, International Brain Injury Association, and Moody Foundation/Galveston Brain Injury Conference; received a stipend as medical director of the Acquired Brain Injury Program at Braintree Rehabilitation Hospital from HealthSouth; received compensation for less than $10 \%$ of his clinical effort for consultations on patients with DoC; and received support from efforts on NIDILRR-funded projects on DoC. N. Schiff serves on an advisory board for Intelect
Medical Inc. and Enspire DBS, Inc (Cleveland); is listed as inventor for multiple patents held by Cornell University; receives royalties for Plum and Posner's Stupor and Coma, Oxford University Press; and holds $0.25 \%$ stock option in Enspire DBS, Inc. (no current value). J. Whyte served on a scientific advisory board for INTRuST; received funding for travel and honoraria from several noncommercial institutions for academic lectures; performs diagnostic behavioral assessments of patients with DoC as $10 \%$ of his clinical effort; received financial support from the NIH, the NIDILRR, and the Patient-Centered Outcomes Research Institute; and has given expert testimony with regard to a patient with DoC. E. Ashman served as Level of Evidence associate editor for Neurology ${ }^{\circledR}$ from 2011 to 2013; provided uncompensated medical-legal reviews for US Air Force legal proceedings as part of his active-duty responsibilities until 2012; received funding from the American Academy of Neurology (AAN) to attend Guideline Development, Dissemination, and Implementation Subcommittee meetings as a subcommittee member and as an ex officio member through January 2018; and has been selected to serve on the editorial board of Neurology: Clinical Practice starting April 2018. S. Ashwal served on a medical advisory board for the Tuberous Sclerosis Association; serves as chief of the Division of Child Neurology, Department of Pediatrics, Loma Linda University School of Medicine; receives royalties for Pediatric Neurology: Principles and Practice, 6th ed.; and received financial support from the NIH NINDS for research on pediatric traumatic brain injury and for use of advanced imaging for detecting neural stem cell migration after neonatal HII in a rat pup model. $\mathrm{R}$. Barbano has served as the associate editor for Neurology: Clinical Practice; has received compensation from law firms and insurance companies for independent medical records reviews and examinations; holds stock options from Visual Dx, Inc.; served on a speakers bureau for Allergan Inc.; and receives research support from the NIH Office of Rare Diseases Research via the Dystonia Coalition, unrelated to the content of this guideline. His spouse has received an NIH grant unrelated to the content of this guideline. F. Hammond is a member of the ACRM Disorders of Consciousness Task Force; served on the US Department of Defence INTRuST Scientific Advisory Council and Avanir Prism II Study Steering Committee; has received royalties from Demos Publishing and Lash Publishing; has received financial support for research from the NIDILRR; holds stock in AbbVie Inc., Amgen Inc., AstraZeneca Plc, Edwards Lifesciences, GW Pharmaceuticals Plc, Intuitive Surgical Inc., Konink Logistics Inc., Merck \& Co. Inc., Pfizer Inc., Sanofi, Thermo Fisher Scientific Inc., UnitedHealth Group, and Zoetis Inc.; and has given legal testimony and acted as legal consultant in legal proceedings on the care needs of individuals with brain injury. S. Laureys performs fMRI, PET, and EEG as $20 \%$ of his clinical effort; received funding from noncommercial institutions such as Belgium's National Fund for Scientific Research, European Commission, Collaborative European NeuroTrauma Effectiveness Research in TBI Project, Human Brain Project, James McDonnell Foundation, European Space 
Agency, "Fondazione Europea di Ricerca Biomedica," BIAL Foundation, Belspo, Wallonia-Brussels Federation Concerted Research Action, and Mind Science Foundation; has served as an editor for Progress in Brain Research and Current Opinion in Neurology; is a member of the Belgian Advisory Committee on Bioethics and Belgian Brain Council and board member of the International Brain Injury Association; elected delegate of the European Academy of Neurology; President of the Association for the Scientific Study of Consciousness and chair of the World Federation of Neurology Applied Research Group on Coma and Disorders of Consciousness; receives royalties for The Neurology of Consciousness, Elsevier, 2015; has given expert testimony with regard to legal cases in Belgium and the Netherlands; and has prepared an affidavit and acted as a witness for legal proceedings in Belgium. G. Ling has served on scientific advisory boards for the NIH National Center for Advancing Translational Sciences (NCATS), the Veterans Administration National Research Advisory Council, Biogen, Facebook B8, KnoLimits, LLC, NED Biosystems, and Camden Partners; served on the board of directors of BioElectron Technologies Corporation (aba Edison Pharmaceuticals); received funding for travel from NIH NCATS, Facebook B8, Edison Pharmaceuticals, KnoLimits, LLC, and Camden Partners; served as a guest editor for Seminars in Neurology and Experimental Neurology; holds a patent (US Patent 7,195,595-B2) with Campbell, M., for a method and apparatus used for monitoring the efficacy of fluid resuscitation; received honoraria from Medtronics, National Defense University (Japan), Sanofi Aventis, Science Teachers, and University of Panama; has been employed by SunQLLC, DrsGSLing, and Center for Brain Health; and holds stock in BioElectron Technologies Corporation (aba Edison Pharmaceuticals), Host Response, NED Biosystems, Camden Partners, Pfizer, and Merck. R. Nakase-Richardson has received financial compensation for travel for speaking at the University of Mississippi Medical Center, New York University, Mayo Clinic, and University of Alabama, Birmingham; and has received research support from General Dynamics Health Solutions from the Defense and Veterans Brain Injury Center within the Defense Health Agency, US Department of Veterans Affairs Health Services Research and Development, Department of Veterans Affairs Rehabilitation Research and Development, and Patient-Centered Outcomes Research Institute. R. Seel has served as both a member and the Chair of the ACRM Disorders of Consciousness Task Force and the ACRM Evidence and Practice Committee; served as an editor for the Journal of Head Trauma Rehabilitation; holds a patent on an electronic driving coach; receives publishing royalties from Pearson; received honoraria for several university-based talks; received payment as a grant reviewer for the Department of Defense Congressionally Directed Medical Research Programs and US Department of Veterans Affairs Rehabilitation Research and Development Service; and has received research funding from the NIDILRR, the NIH, the Centers for Disease Control and Prevention, the Craig H. Neilsen Foundation, and the Shepherd Center Foundation. S. Yablon has served on scientific advisory boards for Allergan Inc., Flowonix Medical Inc., Ipsen Pharma, Medtronic Inc., and Merz Pharmaceuticals $\mathrm{GmbH}$; received travel-related funding from Allergan Inc., Ipsen Pharma, Medtronic Inc., and Merz Pharmaceuticals $\mathrm{GmbH}$; served as associate editor for the journal $P M \nLeftarrow R$ and on the editorial advisory board for the Baylor University Medical Center Proceedings; has received honoraria for presentations given during scientific meetings sponsored or cosponsored by Allergan Inc. and Merz Pharmaceuticals $\mathrm{GmbH}$; performs botulinum neurotoxin procedures for treatment of focal spastic hypertonia ( $<10 \%$ of clinical effort); has received financial research support from Medtronic Inc. and research support from the NIDILRR; and has given expert testimony and acted as legal consultant in legal proceedings. T. Getchius has received financial compensation for travel to speak at the University of Louisville mTBI conference and the New York Academy of Medicine E-GAPPS conferences; has been serving as the vice-chair of the Council of Medical Specialty Societies Clinical Practice Guideline Component Group from November 2013 to present; has received research support (all monies directed to the AAN) from the Centers for Disease Control and Prevention for a grant for muscular dystrophy guideline development, dissemination, and implementation; and is a past employee of the AAN. G. Gronseth serves on the Neurology Now editorial advisory board and receives financial support for serving as chief evidence-based methodologist for the AAN. M. Armstrong serves on the Level of Evidence editorial board for Neurology (but is not compensated financially) and serves as an evidence-based medicine methodologist for the AAN. Go to Neurology.org/ $\mathrm{N}$ for full disclosures.

\section{Disclaimer}

Clinical practice guidelines, practice advisories, systematic reviews, and other guidance published by the American Academy of Neurology (AAN) and its affiliates and the American Congress of Rehabilitation Medicine (ACRM) are assessments of current scientific and clinical information provided as an educational service. The information (1) should not be considered inclusive of all proper treatments, methods of care, or as a statement of the standard of care; (2) is not continually updated and may not reflect the most recent evidence (new evidence may emerge between the time information is developed and when it is published or read); (3) addresses only the question(s) specifically identified; (4) does not mandate any particular course of medical care; and (5) is not intended to substitute for the independent professional judgment of the treating provider, as the information does not account for individual variation among patients. In all cases, the selected course of action should be considered by the treating provider in the context of treating the individual patient. Use of the information is voluntary. AAN provides this information on an "as is" basis, and makes no warranty, expressed or implied, regarding the information. The AAN and ACRM specifically disclaim any warranties of merchantability or fitness for a particular use or purpose. The AAN and ACRM assume no responsibility for any injury or damage to persons or property arising out of or related 
to any use of this information or for any errors or omissions. This document does not reflect the official policy or opinions of the National Institute on Disability, Independent Living, and Rehabilitation Research (NIDILRR) or the US Health and Human Services Department (HSS) and does not constitute an endorsement by NIDILRR, HHS, or other components of the federal government.

\section{Conflict of interest}

The American Academy of Neurology (AAN) and the American Congress of Rehabilitation Medicine (ACRM) are committed to producing independent, critical, and truthful clinical practice guidelines (CPGs). Significant efforts are made to minimize the potential for conflicts of interest to influence the recommendations of this CPG. To the extent possible, the AAN and the ACRM keep separate those who have a financial stake in the success or failure of the products appraised in the CPGs and the developers of the guidelines. Conflict of interest forms were obtained from all authors and reviewed by an oversight committee prior to project initiation. The AAN and the ACRM limit the participation of authors with substantial conflicts of interest. The AAN and ACRM forbid commercial participation in, or funding of, guideline projects. Drafts of the guideline have been reviewed by at least $3 \mathrm{AAN}$ committees, at least 2 ACRM committees, a network of neurologists, Neurology peer reviewers, and representatives from related fields. The AAN Guideline Author Conflict of Interest Policy can be viewed at aan.com. For complete information on this process, access the $2011 \mathrm{AAN}$ process manual, as amended (aan.com/Guidelines/Home/Development).

Received December 12, 2017. Accepted in final form May 22, 2018.

\section{References}

1. Plum F, Posner JB. The Diagnosis of Stupor and Coma, 3rd ed. Philadelphia: FA Davis; 1982

2. Ashwal S, Cranford R, Bernat JL, et al. Medical aspects of the persistent vegetative state (first of two parts). N Engl J Med 1994;330:1499-1508.

3. Giacino JT, Ashwal S, Childs N, et al. The minimally conscious state: definition and diagnostic criteria. Neurology 2002;58:349-353.

4. Sazbon L, Groswasser Z. Medical complications and mortality of patients in the postcomatose unawareness (PC-U) state. Acta Neurochir 1991;112:110-112.

5. Laureys S, Celesia GG, Cohadon F, et al; for the European Task Force on Disorders of Consciousness. Unresponsive wakefulness syndrome: a new name for the vegetative state or apallic syndrome. BMC Med 2010;8:68.

6. National Institutes of Health. Consensus conference: rehabilitation of persons with traumatic brain injury: consensus development panel on rehabilitation of persons with traumatic brain injury. JAMA 1999;282:974-983.

7. The Quality Standards Subcommittee of the American Academy of Neurology. Practice parameter: assessment and management of patients in the persistent vegetative state (summary statement). Neurology 1995;45:1015-1018.

8. Jennett B. The vegetative state. J Neurol Neurosurg Psychiatry 2002;73:355-357.

9. Tresch DD, Sims FH, Duthie EH, Goldstein MD, Lane PS. Clinical characteristics of patients in the persistent vegetative state. Arch Intern Med 1991;151:930-932.

10. Cranford RE. The persistent vegetative state: the medical reality (getting the facts straight). Hastings Center Rep 1988;18:27-32.

11. Spudis EV. The persistent vegetative state: 1990. J Neurol Sci 1991;102:128-136.

12. Strauss DJ, Ashwal S, Day SM, Shavelle RM. Life expectancy of children in vegetative and minimally conscious states. Pediatr Neurol 2000;23:312-319.
13. Schnakers C, Vanhaudenhuyse A, Giacino J, et al. Diagnostic accuracy of the vegetative and minimally conscious state: clinical consensus versus standardized neurobehavioral assessment. BMC Neurol 2009;9:35.

14. Childs NL, Mercer WN, Childs HW. Accuracy of diagnosis of persistent vegetative state. Neurology 1993;43:1465-1467.

15. Andrews K, Murphy L, Munday R, Littlewood C. Misdiagnosis of the vegetative state: retrospective study in a rehabilitation unit. BMJ 1996;313:13-16.

16. Nakase-Richardson R, Yablon SA, Sherer M, Evans CC, Nick TG. Serial yes/no reliability after traumatic brain injury: implications regarding the operational criteria for emergence from the minimally conscious state. J Neurol Neurosurg Psychiatry 2008;79:216-218.

17. Seel RT, Sherer M, Whyte J, et al. Assessment scales for disorders of consciousness: evidence-based recommendations for clinical practice and research. Arch Phys Med Rehabil 2010;91:1795-1813.

18. Rodriguez Moreno D, Schiff ND, Giacino J, Kalmar K, Hirsch J. A network approach to assessing cognition in disorders of consciousness. Neurology 2010;75:1871-1878.

19. Coleman MR, Davis MH, Rodd JM, et al. Towards the routine use of brain imaging to aid the clinical diagnosis of disorders of consciousness. Brain 2009; 132:2541-2552.

20. Schiff ND, Rodriguez-Moreno D, Kamal A, et al. fMRI reveals large-scale network activation in minimally conscious patients. Neurology 2005;64:514-523.

21. Laureys S, Faymonville ME, Degueldre C, et al. Auditory processing in the vegetative state. Brain 2000;123:1589-1601.

22. Childs NL, Mercer WN. Brief report: late improvement in consciousness after posttraumatic vegetative state. N Engl J Med 1996;334:24-25.

23. Giacino J. Revisiting the vegetative state: major developments over the last decade. In: McDeavitt J, ed. State of the Art Reviews in Physical Medicine and Rehabilitation: Traumatic Brain Injury. Philadelphia: Hanley and Belfus; 2001:399-415.

24. Giacino JT, Katz DI, Schiff ND, et al; for the Guideline Development, Dissemination, and Implementation Subcommittee of the American Academy of Neurology. Practice guideline update recommendations summary: disorders of consciousness: report of the Guideline Development, Dissemination, and Implementation Subcommittee of the American Academy of Neurology; the American Congress of Rehabilitation Medicine; and the National Institute on Disability, Independent Living, and Rehabilitation Research. Neurology 2018;91:450-460.

25. American Academy of Neurology. Clinical Practice Guideline Process Manual. $2011 \mathrm{ed}$. St. Paul: American Academy of Neurology; 2011. Available at: https://www.aan.com/ policy-and-guidelines/guidelines/about-guidelines2/. Accessed September 2, 2016.

26. Guyatt GH, Oxman AD, Vist GE, et al. GRADE: an emerging consensus on rating quality of evidence and strength of recommendations. BMJ 2008;336:924-926.

27. Habbal D, Gosseries $\mathrm{O}$, Noirhomme $\mathrm{Q}$, et al. Volitional electromyographic responses in disorders of consciousness. Brain Inj 2014;28:1171-1179.

28. Charland-Verville V, Lesenfants D, Sela L, et al. Detection of response to command using voluntary control of breathing in disorders of consciousness. Front Hum Neurosci 2014;8:1020.

29. Forgacs PB, Conte MM, Fridman EA, Voss HU, Victor JD, Schiff ND. Preservation of electroencephalographic organization in patients with impaired consciousness and imaging-based evidence of command-following. Ann Neurol 2014;76:869-879.

30. Casarotto S, Comanducci A, Rosanova M, et al. Stratification of unresponsive patients by an independently validated index of brain complexity. Ann Neurol 2016;80:718-729.

31. Estraneo A, Loreto V, Guarino I, et al. Standard EEG in diagnostic process of prolonged disorders of consciousness. Clin Neurophysiol 2016;127:2379-2385.

32. Naro A, Russo M, Leo A, et al. Cortical responsiveness to nociceptive stimuli in patients with chronic disorders of consciousness: do C-fiber laser evoked potentials have a role? PLoS One 2015;10:e0144713; eCollection 2015.

33. Monti MM, Rosenberg M, Finoia P, Kamau E, Pickard JD, Owen AM. Thalamofrontal connectivity mediates top-down cognitive functions in disorders of consciousness. Neurology 2015;84:167-173.

34. Lesenfants D, Habbal D, Chatelle C, Schnakers C, Laureys S, Noirhomme Q. Electromyographic decoding of response to command in disorders of consciousness. Neurology 2016;87:2099-2107.

35. Chennu S, Finoia P, Kamau E, et al. Dissociable endogenous and exogenous attention in disorders of consciousness. Neuroimage Clin 2013;3:450-461.

36. Kotchoubey B, Yu T, Mueller F, Vogel D, Veser S, Lang S. True or false? Activations of language-related areas in patients with disorders of consciousness. Curr Pharm Des 2014;20:4239-4247.

37. Rosazza C, Andronache A, Sattin D, et al. Multimodal study of default-mode network integrity in disorders of consciousness. Ann Neurol Epub 2016 Mar 11.

38. Gosseries O, Schnakers C, Ledoux D, et al. Automated EEG entropy measurements in coma, vegetative state/unresponsive wakefulness syndrome and minimally conscious state. Funct Neurol 2011;26:25-30.

39. Holler Y, Bergmann J, Kronbichler M, et al. Preserved oscillatory response but lack of mismatch negativity in patients with disorders of consciousness. Clin Neurophysiol 2011;122:1744-1754.

40. Stender J, Gosseries O, Bruno MA, et al. Diagnostic precision of PET imaging and functional MRI in disorders of consciousness: a clinical validation study. Lancet 2014; 384:514-522. 


\section{Neurology}

Comprehensive systematic review update summary: Disorders of consciousness:

Report of the Guideline Development, Dissemination, and Implementation

Subcommittee of the American Academy of Neurology; the American Congress of Rehabilitation Medicine; and the National Institute on Disability, Independent Living, and Rehabilitation Research

Joseph T. Giacino, Douglas I. Katz, Nicholas D. Schiff, et al.

Neurology 2018;91;461-470 Published Online before print August 8, 2018

DOI 10.1212/WNL.0000000000005928

This information is current as of August 8, 2018

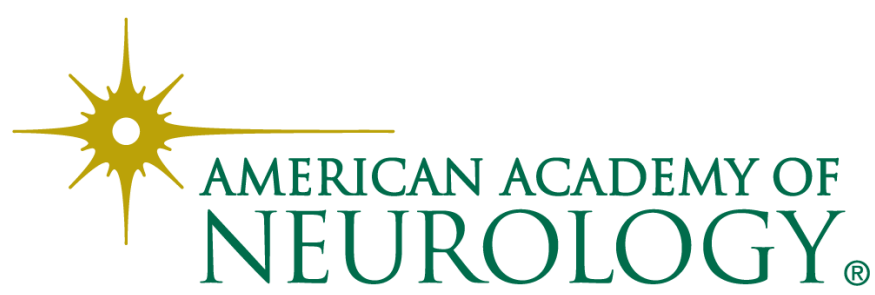




\section{Updated Information \& Services}

References

Citations

Subspecialty Collections

Permissions \& Licensing

Reprints including high resolution figures, can be found at: http://n.neurology.org/content/91/10/461.full

This article cites 36 articles, 11 of which you can access for free at: http://n.neurology.org/content/91/10/461.full\#ref-list-1

This article has been cited by 5 HighWire-hosted articles: http://n.neurology.org/content/91/10/461.full\#\#otherarticles

This article, along with others on similar topics, appears in the following collection(s):

All Clinical Neurology

http://n.neurology.org/cgi/collection/all_clinical_neurology All clinical neurophysiology

http://n.neurology.org/cgi/collection/all_clinical_neurophysiology All Pediatric

http://n.neurology.org/cgi/collection/all_pediatric

Brain trauma

http://n.neurology.org/cgi/collection/brain_trauma

Plasticity

http://n.neurology.org/cgi/collection/plasticity

Information about reproducing this article in parts (figures,tables) or in its entirety can be found online at:

http://www.neurology.org/about/about_the_journal\#permissions

Information about ordering reprints can be found online:

http://n.neurology.org/subscribers/advertise

Neurology ${ }^{\circledR}$ is the official journal of the American Academy of Neurology. Published continuously since 1951, it is now a weekly with 48 issues per year. Copyright . All rights reserved. Print ISSN: 0028-3878. Online ISSN: 1526-632X.

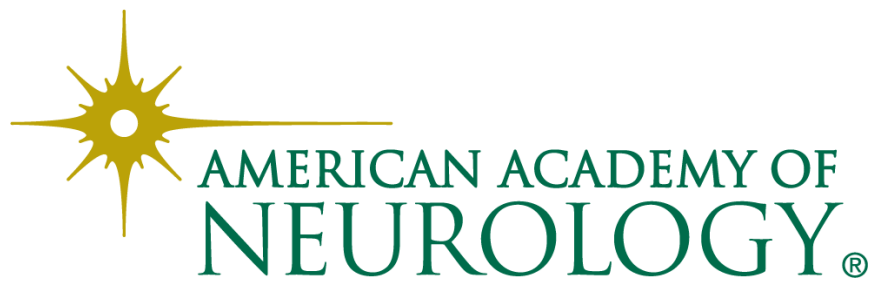

